\title{
Design as research
}

\section{Speaking plainly}

Since I seem to have started the design/research hare running in this journal (arq 1/1) and have been quoted, not always accurately, on more than one occasion since, I feel it necessary to try to set the record straight. My original article discussed the general question of design in relation to the UK universities' Research Assessment Exercise and not simply whether design may or may not be considered research. It also attempted to consider the possible ways in which university schools of architecture might adjust to the pressures of the RAE and perhaps for this reason my views about design and research did not come through as clearly as they might. It is very frustrating to be told that one is wrong and then have one's own arguments used to explain way. In this case it is the other way round but just as bad: Brian Lawson (arq 3/1) makes an argument for something with which I have not disagreed but then says that I have argued against it.

Let me therefore put my position as plainly as I can. I did not argue against the possibility of design being classed as research, only against anything that resembles normal architectural practice. I believe that design can be considered as the equivalent of research under certain circumstances which, for the sake of the RAE, need to be clearly defined. Brian Lawson quotes the passage defining acceptable design as that which leads to 'new or substantially improved insights' and I have no objection to that. Do not my words 'new approaches to design or new design forms based upon an improved understanding of the problem' (arq 1/1) suggest something very similar? I also like to think that some of the suggestions that I made in my article anticipated the ideas about a bridge between research and practice expressed in you recent leader (arq 3/1). Moreover, my paper 'Doctorates in design and architecture', to the $1996 \mathrm{EAAE}$ conference in Delft, not only argued for the possibility of design PhDs but tried to set out some criteria on which these might be judged. It is similar criteria that I believe would qualify design as a research equivalent exercise for the RAE, although these are certainly open to debate.

Brian Lawson clearly believes we hold different views but I have no idea where he thinks his views differ from mine. If he would be specific the debate might advance a little. However, it occurs to me that we may be interpreting the phrase 'substantially new insights' in quite different ways: or, if we are not, others may. Such a phrase may not mean anything more than it does when applied to research. Is not the researcher trying to see things in a different or substantially new way? However, when we see what we regard as a good painting, hear a good piece of music or read a good novel or poem it is surely because the work of art has given us new insights; insights that we would not have had otherwise. Does not the artist say 'this is how I see the world', inviting the observer to see it that way also? The problem with the phrase 'new insights' is that it may be applied to architecture in such different ways that its meaning is not clear. If architecture is an art, then good architecture may be providing new insights in

\section{Uninhabited photographs}

just that way, but let us be clear that it is then art and not research.

This raises a quite different question which is whether the practice of an art, in departments concerned with such matters, should be funded through the RAE. Is having 'practising artists' in such departments a good thing; do they make good, inspiring teachers or are they valuable to their departments in some other way? If you believe that it is important to have composers in departments of music, writers of novels, poems or plays in departments of English literature or drama, and architects in departments of architecture, then that is a reasonable point of view which may be argued. I have no objection to such an argument only to the form in which it is made. Let us keep the argument clear and not try to pretend that this activity is research; it is not. However, in architecture the debate is perhaps muddied by the extent to which one believes that the subject should be taught as an art, unencumbered by inconvenient practical considerations, or at the other extreme, that learning to deal with such matters is the sine qua non of an architectural graduate.

DAVID YEOMANS Liverpool

David Yeomans is a Research Fellow at the University of Liverpool

\section{The photographer replies}

As author and photographer of the paper on Rudolphe Luscher's College de Corsier (arq 3/2), I would like to comment on the issue of uninhabited photographs raised so sternly in your editorial.

My visit to the school was brief 
and took place at a weekend with the architect. In general I prefer to include people in my photographs, but there are several difficulties beyond this simple matter of timing. The widely preferred method of photographing buildings is cumbersome and slow, involving large format rising-front cameras and extreme wide-angle lenses. I started with a Sinar, but now use a more compact Corfield. The camera must be set up on a tripod with its spirit level to get it accurately vertical, and the shot must be composed and the light read before exposure takes place. For depth of field the lens must be stopped-down, necessitating exposures of half a second or more for interiors with normal film speeds (flash is no good as it cancels natural light). At this shutter setting anyone moving becomes a blur (photo a), but sometimes they halt for a lucky moment and you press the shutter (photo b). Otherwise they must be asked to stand still, but with crowds this is obviously impractical.

In institutions like schools, the architecturally important linking spaces are typically either full of kids rushing from class to class too chaotic - or two minutes later completely empty. To show them in

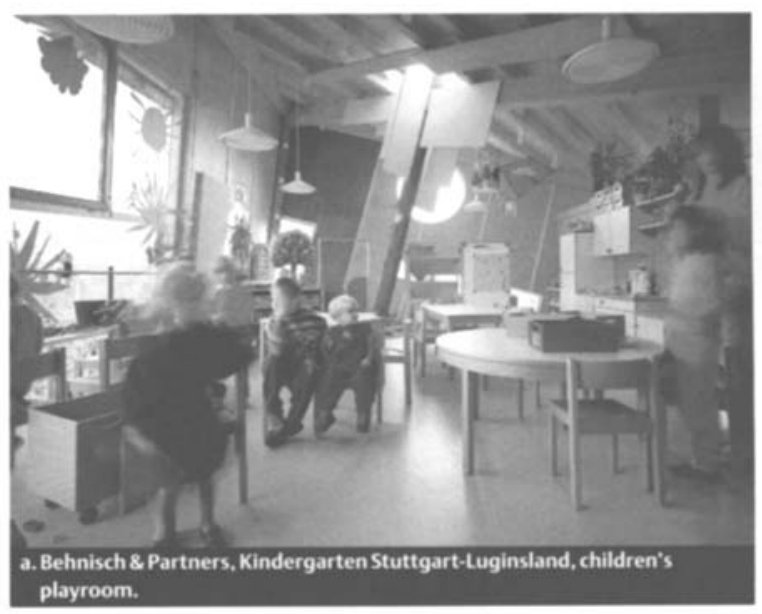

use you have to be ready when the bell goes, and may obtain two or three shots if lucky (photo c). If you want a shot in the classroom, teachers may refuse, claiming you need parents' permission, but if allowed, the setting-up of the camera makes pupils selfconscious, and younger children tend to gesticulate. You have to be there some time before they settle down and behave naturally (photo d). You can of course take your own people and add them where you like (photo e.), but when they appear in too many shots your artifice is exposed! Finally, when people are included, they tend to
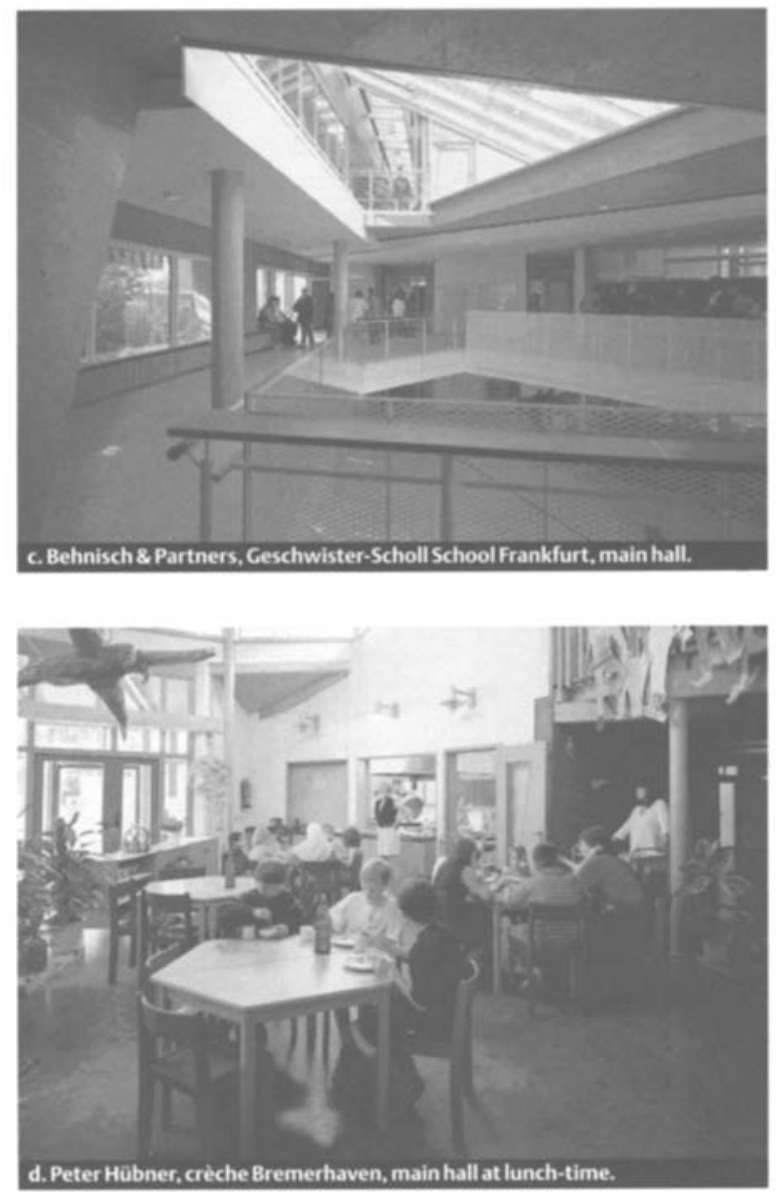

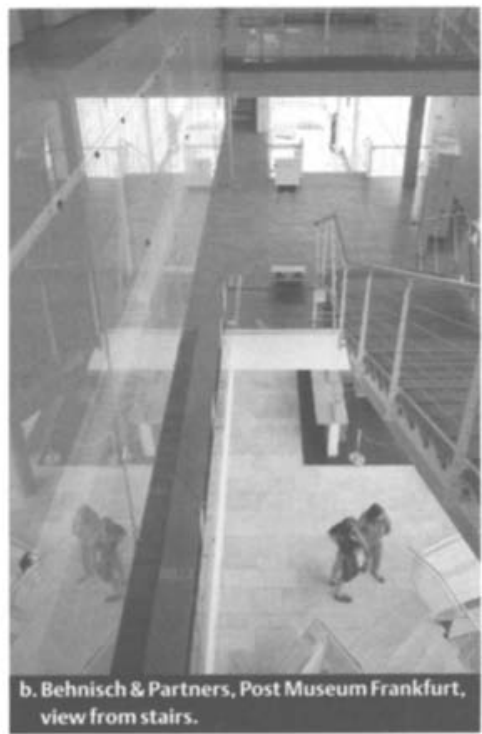

appear rather small (f and g) due to the foreground priority of foreground of wide-angle lenses ( $47 \mathrm{~mm}$ with $6 \times 7$ format on a Corfield), but the wide-angle lens is nonetheless essential to show enough of the building.

The move away from chemically based film and towards digital recording is already upon us and will take over in the next few years, being potentially cheaper, more manipulable and instantaneous - so you know what you've got while on the site. It will presumably allow faster exposures to solve the main problem outlined above, and also more manipulation of contrast in light levels - the other great bugbear in photographing interiors. But finally the cumbersome process of setting up the camera remains, as does the effect of choosing the position and framing the shot. The only alternative would be a small and mobile camera with fast film and without so-called perspective 'correction' (vertical perspective exists - it is repressed by the risingfront camera).

A style of photography catching 


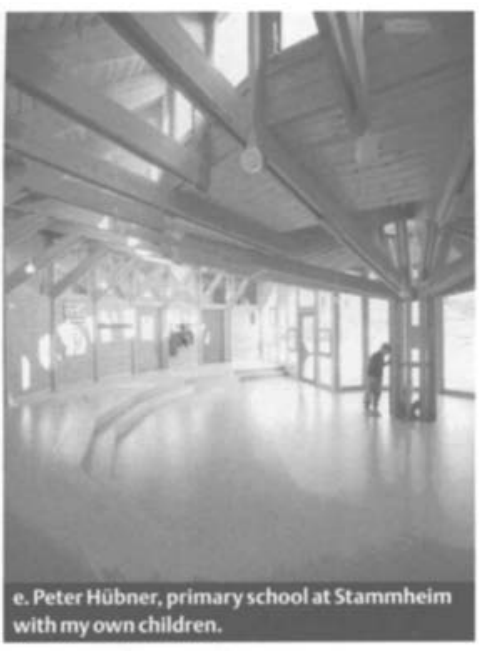

the moment - like that of Henri Cartier-Bresson, who used a Leica could indeed be encouraged for architecture, and could produce a gain in spontaneity if offset by loss of detail. But I do not know of any editor encouraging this approach, or of a serious architectural photographer moving in this direction. The Architectural Review once asked the gifted photojournalist Erika Sulzer-Kleinemeier to photograph a school by Lucien Kroll, and the shots of the pupils were wonderful, but there was not enough sense of the building, and the experiment was not deemed a success.
Technical questions apart, I think there is a more fundamental issue. Photography makes a dynamic experience static for the page, and the image departs from its source and takes on a life of its own, with its own rules and conventions. We have come to expect an architectural photograph to be still and orderly, not the bustle of life arrested. We prefer to concentrate on the object as unchanging mute witness of changing life within. We seek, all too readily, the illusion of purity that the architect also enjoys as a golden moment of perfection: those few hours caught between the builder clearing out his rubbish and the messy inhabitants moving in, trying to make it their own. It is a moment of utopian control, when the tide of life (and rot and chaos) is held in check. The camera captures it admirably.

After 25 years of reporting on architecture through print and photographs, I am rather astonished that I ever felt these media to be anything like 'transparent', and it seems to me now rather a wonderful thing if we can even begin to know a building through drawings and photographs, let alone understand it fully. It has also become
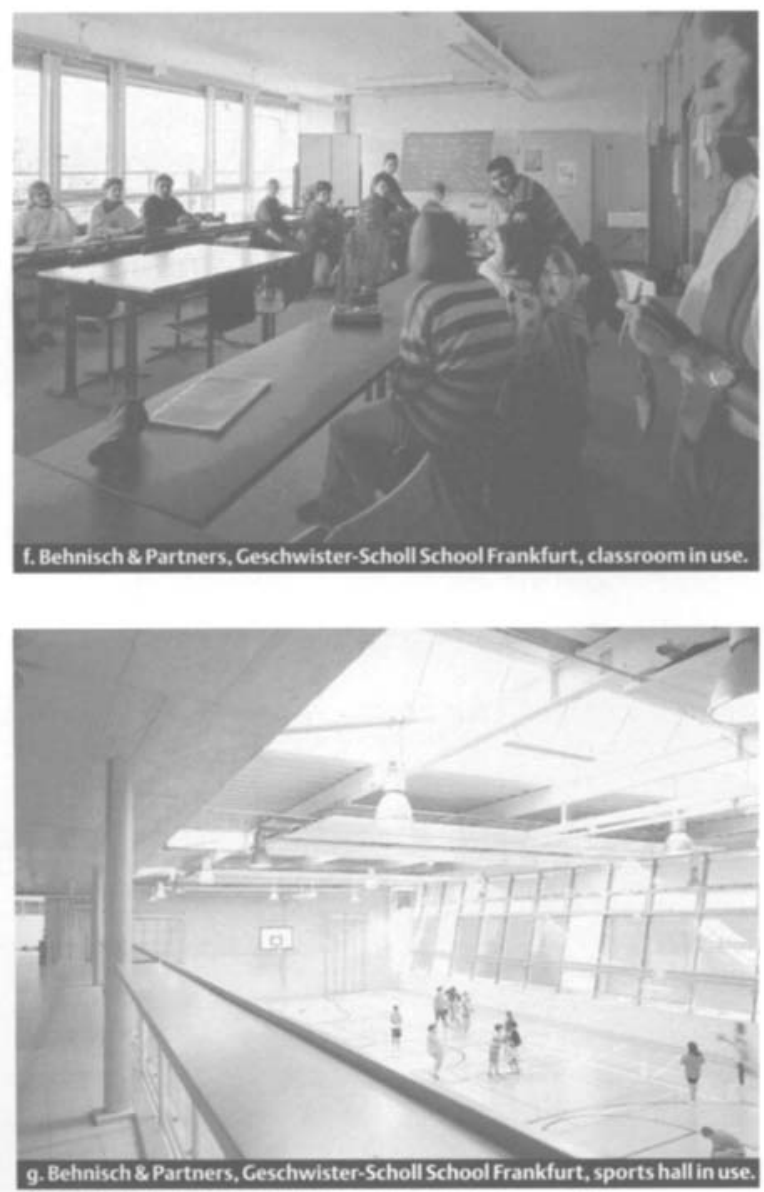

increasingly clear to me that photography has radically influenced the dissemination of architecture, taking buildings out of their contexts and setting an evolutionary trend in favour of the photogenic. As we now know from colourful restorations, the Weissenhofsiedlung only became 'The White Architecture' thanks to black-and white photographs, and Bruno Taut's fabled experiments with colour at Magdeburg in the 1920 are lost simply for lack of a recording medium. Did not the revival of colour in architecture in the 1970 directly follow the availability of cheap colour printing?

PETER BLUNDELL JONES Sheffield

Peter Blundell Jones is Professor of Architecture at the University of Sheffield

\section{Critical view}

Re. your leader in your fine new issue, do look at The Architects Journal 20.9.72 pp 637-678, esp pp. 654-5 where the question is raised, and pp.656-7 where it is looked at rather differently, and pp.670-1 \& 674 with not just people but signs of occupancy.

(If only magazines in these ancient days had published with more panache it could have been even more as the author had hoped!)

\section{JOHN MCKEAN} Brighton

John McKean, a Professor of Architectural History at the University of Brighton, is referring to a seminal issue of The Architects' Journal which featured an extended review (by him) of the recently completed University of Essex and, in particular, to certain illustrations and their captions. Juxtaposing images from architecture magazines with 'the reality' he commented on '... Pretty shapes and patterns are required by "art" magazines ... a muddling full page view from The Architectural Review ... the photographers' telephoto images far removed from perceived reality...'

Letters should be sent to Peter Carolin arq. c/o University of Cambridge Department of Architecture, 1 Scroope Terrace, Cambridge CB2 1pX, UK $F+44(0) 1223332960$ or Emailed to pc207@hermes.cam.ac.uk The Editors reserve the right to shorten letters. 